\title{
Playing through the Pain: A University-Based Study of Sports Injury
}

\author{
Geneviève Jessiman-Perreault ${ }^{1}$, Jenny Godley ${ }^{2 *}$ \\ ${ }^{1}$ Department of Community Health Sciences, University of Calgary, Calgary, Alberta \\ ${ }^{2}$ Department of Sociology, University of Calgary, Calgary, Alberta \\ Email: "jgodley@ucalgary.ca
}

Received 18 July 2016; accepted 1 August 2016; published 4 August 2016

Copyright (C) 2016 by authors and Scientific Research Publishing Inc.

This work is licensed under the Creative Commons Attribution International License (CC BY). http://creativecommons.org/licenses/by/4.0/

(c) (i) Open Access

\section{Abstract}

This paper presents findings from a survey that assessed university students' opinions about sports injury. Specifically, the paper seeks to understand whether university students who participate in sports at different levels would choose to participate while injured, and who or what influences these decisions. An online survey was administered to 275 university students. Results indicate that the concept of the "sports ethic" was a major determinant in respondents' reported willingness to play through injuries. The sports ethic influenced participants at all levels of sport (casual, amateur, and professional). We suggest that once the sports ethic is internalized, it may counter the potential buffering capacity of injury prevention programs. The implications of these findings for injury prevention education are assessed.

\section{Keywords}

\section{Sports Injury, Sports Ethic, Injury Prevention}

\section{Introduction}

Sports injury is regarded by many as an unavoidable part of sports participation, and has been a subject of sociological examination for over twenty years (Nixon, 1992; Nixon, 1993; Curry, 1993; Curry \& Strauss, 1994). Although media stories often focus on injuries in elite sports, sports-related injury occurs at all levels of sports and in all age groups. Young (1993) gives the example that all National Football League (NFL) players can expect to get at least one injury in their four-month season. However, sports injury is also pervasive at the amateur

${ }^{*}$ Corresponding author. 
level and frequently occurs during casual play. According to one 1990 study, nearly half of all non-competitive athletes suffer injuries that prevent temporary participation (Hardy \& Crace, 1990).

Sports injury also occurs in almost every age group. In an international meta-analysis of injury incidence rates among children and youth, researchers found that on average boys in ice hockey experienced between 5 - 34.4 injuries per 1000 hours of exposure, 3.4 - 13.3 injuries in rugby and $2.3-7.9$ injuries in soccer. For girls, soccer had the highest incidence of injuries (2.5 - 10.6 per 1000 hours of exposure). Girls playing basketball had between 3.6 and 4.1 injuries and gymnasts suffered 0.5 - 4.1 injuries per 1000 hours of exposure (Caine, Maffulli, \& Caine, 2008). According to Pargman, the number of sports-related injuries and illnesses at all ages has increased over the past 15 to 20 years (Pargman, 2007). Athletes as young as nine years of age have been shown to accept pain and injury as being an inevitable and acceptable part of the sport (Singer, 2004). Multiple theories have been postulated to explain how this attitude is instilled within young sports participants at all levels of competition.

Some researchers have argued that the media has normalized injury as routine for athletes (Morse, 1983; Nixon, 1993; Young, 2012). In 1979, Jack Youngblood, a defensive end NFL player, played in three games and a major tournament on a broken leg that was braced and taped, but not medically treated until the end of the season. Kerri Strug famously vaulted in the 1996 Olympic Games with two torn ligaments in her ankle. The media lauded both athletes as heroes and they were praised for their commitment to their sport. Strug was featured on the cover of the Daily News Sport in 1996, waving to the crowd while being carried by her coach, her leg bound, underneath the headline "Kerri Strug stands tall on injured ankle, leads U.S. gymnastics to team gold at 1996 Atlanta Olympics” (Bondy, 1996). This glorification of injury is by no means limited to high-stake competitions. Recently, Australian university rugby player Georgia Page became an internet sensation when she refused to stop playing after breaking her nose during a match against the USA. Page was dubbed as "the Rugby War Goddess" and was praised for making two more crushing tackles while blood streamed down her face (Groom, 2015). This type of media attention may reinforce behaviour that could be hazardous to young players' physical and mental health (Granquist, Harrison-Utley, Kenow, \& Ostrowski, 2014).

There is a growing push in Canadian society today to get kids active in order to curb the rates of childhood obesity. In 2010, all of the Federal, Provincial and Municipal Ministries of Health or Health Promotion adopted a framework to promote healthy body weight with a particular emphasis on curbing childhood obesity (Public Health Agency of Canada, 2012). This major push to get children active could have negative consequences if the sports culture that they are inducted into is a culture which pushes participants to disregard their physical limits and injuries in order to compete. Safe Kids, a non-profit organization dedicated to preventing childhood accidents, reported that in a survey of 752 youth sports coaches in the USA, almost half reported being pressured, most notably by parents (but sometimes by the child), to play an injured child during a game (Safe Kids, 2014). Therefore, the source of the push for athletes to play through injury may not be coming directly from the athlete themselves but from their sport social networks. These networks can include parents, coaches, teammates, and trainers (Nixon, 1992).

This paper will examine whether university students who participate in sports at a variety of skill levels would agree to play while injured, and what influences these decisions. The goal of this paper is to first assess whether respondents perceive that they would play while injured. Second, we will investigate the psychological, situational, and inter-personal factors that influence participants’ perceptions of playing while injured.

\section{Literature Review}

To better understand why those who participate in sports might willingly employ behaviours that could harm or injure their bodies and health, we examine the following four concepts from the literature: the sports ethic; athletic identity; the culture of risk; and the influence of others. These concepts, which are linked, have each been hypothesized to explain why players are willing to play while injured (Hughes \& Coakley, 1991; Nixon, 1992; Safai, 2003).

\subsection{The Sports Ethic}

The term "the sports ethic" was originally coined by Robert Hughes and Jay Coakley to synthesize the core norms that participants use to identify themselves as members of sports culture (Hughes \& Coakley, 1991). Four core ideas underlie the sports ethic: making sacrifices for the game; striving for distinction; accepting risks and playing through the pain; and refusing to accept limits in the pursuit of possibilities (Hughes \& Coakley, 1991). 
First, the sports ethic involves making sacrifices for your sport. In order to be considered a "real athlete," or one worthy of development and attention, you must prioritize your sport above all else. Athletes must demonstrate an unwavering commitment to their sport and in doing so must make sacrifices. The second idea underlying the sports ethic involves striving for distinction. The ultimate marker of success in sport for athletes is winning, which includes winning competitions, breaking records, and pushing the limits of the sport. The third idea underlying the sports ethic is of particular focus in this paper, as it involves accepting the risks associated with sport and playing through the pain. Hughes and Coakley argue that athletes accept risks and play through pain both because of internal and external (teammates and coaches) pressures (1991). The final idea underlying the sports ethic is that athletes will accept no obstacle while pursuing their sport, even when the odds are against them, for instance, after suffering a debilitating injury.

Over conformity to the sports ethic can have negative physical and emotional consequences (Granquist, Harrison-Utley, Kenow, \& Ostrowski, 2014). Some examples of over conformity to the sport ethic include: risking injury to compete; avoiding medical treatment; winning regardless of physical costs; playing through the pain; avoiding using protective gear; and avoiding taping previous injuries (Hughes \& Coakley, 1991; Miller, 2008).

\subsection{Athletic Identity}

Athletic identity is defined by Brewer, Van Raalte and Linder as "the degree to which an individual identifies with the athletic role” (1993, p. 237). While a strong athletic identity can provide motivation and drive that is needed to succeed in sport, it can also be detrimental and lead players to push their bodies beyond what is safe in order to maintain their athletic identity.

According to Malcolm (2003), those who identify strongly with their athletic identity are more likely to adopt an attitude of "toughing out" an injury. These individuals are also more likely to participate in their sport to an extreme where it may be physically damaging (Brewer, van Raalte, \& Linder, 1993). Playing through the pain for these participants may be a rational decision in the short term to maintain their athletic identity, but they may not be emotionally or psychologically prepared if they sustain a debilitating injury that forces them to leave their sport and give up their athletic identity (Leddy, Lambert, \& Ogles, 1994).

Curry and Strauss (1994) and Roderick, Waddington and Parker (2000) studied athletes at American colleges and universities and English professional soccer players respectively, and found that injury was accepted as a part of the game and players who did not react as much to pain and injury were shown to be possessing the values of "true athletes” (Curry \& Strauss, 1994; Roderick, Waddington, \& Parker, 2000).

Young (2012) has also suggested that the athletic identity is part of hegemonic masculinity. He suggests that playing through the pain or accepting no limits in the pursuit of winning can be seen as a way to prove one's prowess or maleness (Young, 2012). Young writes: "Sport thus becomes viewed as a context for the expression and reproduction of hegemonic forms of masculinity where violence, pain, and injury are legitimate and, indeed, "make sense.” Male athletes unwilling to conform to such standards of "manliness” may become mocked, ostracized or even drop out altogether” (Young, 2012: p. 103).

Moreover, it has been suggested that since sport has traditionally been seen as a male pursuit (Hargreaves, 1994; Kimmel, 2005; Messner, 1989), it has been built on the male's social expectations of the sport. Therefore, the concept of the athlete is tightly connected with characteristics of hegemonic masculinity (Kimmel, 2005). This relationship between traditional expressions of masculinity and sport has been called the masculinity-sport nexus (Berg, Migliaccio, \& Anzini-Varesio, 2014). This nexus is often "invisible” to the general population, and the norms are seen as "part of the game” rather than being distinctly gendered (Connell, 2005). This nexus both excludes and restricts women in sport.

\subsection{Culture of Risk}

Nixon (1993) and Safai (2003) have written about a separate but related concept that must be addressed when examining why sports' participants play while injured-the concept of sport being a “culture of risk”. A culture of risk is described as a set of beliefs that participants are socialized into that encompasses the acceptance of risk, pain, and injury (Nixon, 1993). The emphasis in these beliefs is on the importance of playing while injured and playing through the pain. This culture is shown when injured players who take themselves out of a competition or game are mocked by others in the athletic community and sometimes restricted from certain benefits (such as placement in line up, or a starting position) and when those who play through injury are regarded as heroes (Gi- 
nis \& Leary, 2004).

Young explains: “... sport occurs in a cultural context that normalizes and glorifies risk, pain, and injury.” (Young, 2012: p. 102). Thus the culture of risk creates an environment where players are encouraged to participate in a sport while injured.

\subsection{Influence of Others}

According to Malcom (2006), individuals are socialized into playing through pain by parents, coaches, officials, teammates, and others involved in the sport. Specifically, coaches socialize their players by ignoring their complaints about pain. Teammates do so by downplaying previous injuries, and harassing those who complain about injuries (Malcom, 2006). Even trained medical professionals such as physicians can shape a participant's decision to play through pain. For example, when asked to comment on Celtics point guard Rajon Rondo's decision to continue to play in the fourth quarter after dislocating his shoulder in the third, Celtics chief medical officer Brian P. McKeon was quoted saying "Part of what makes an athlete an athlete is the ability to play through pain" (Brogan, 2012). The example set by Rondo and McKeon has a trickle-down effect on amateurs and young adults who idolize sports stars such as Rondo and consume sports media. Nixon (1992) also argues that athletes are surrounded by social relationships ("sportsnets") that may pressure them to play while injured (also see Young, 2012).

In conclusion, while many players may believe that it is their own decision whether they will play while injured or not, their socialization into the sports ethic and the culture of risk that sport is embedded in, along with their own sense of their athletic identity and the influence of others, may create a situation where the only choice for them is to continue to play. Pain is normalized through external institutional settings as well as self-imposed values that athletes accept as being a part of sports early on (Young, 2012). Young writes, "Such normalization processes and value systems, which make themselves known to many recreational and amateur athletes as choices, become systematized as prerequisites at the elite, and certainly the professional level” (Young, 2012: p. 103). Our study will examine whether these processes and value systems extend to casual and recreational sports participants.

\subsection{Research Objectives}

Each of these factors - the sports ethic, athletic identity, the culture of risk, and the influence of others-may contribute to an individual's decision to play while injured. Previous studies have examined these factors in the context of high level professional athletes, usually examining athletes of one gender within a specific sport. For example, Malcom (2006) examined female baseball players, Sabo (1986) examined male football players, and Berg, Migliaccio and Anzini-Vanesio (2014) examined female football players. For this project, we surveyed students of both sexes, as well as those who participate at various levels and in various types of sports. The aim of our study is to better identify whether sports participants across the ability spectrum are at risk to play through injury. Understanding who is willing to play while injured and what influences these decisions may allow for researchers and practitioners to better target interventions to those individuals in an attempt to reduce injury. This paper examines two main research questions using data from University of Calgary students:

1) Who reports being willing to play while injured?

2) Why do they report that they are willing to play through injury, i.e., who or what influences this decision?

\section{Methods}

\subsection{Survey-Respondents and Instrument}

We recruited volunteer respondents $(\mathrm{N}=275)$ to complete a novel online self-administered survey. Both undergraduate and graduate University of Calgary students were targeted through a variety of recruitment methods, including: disseminating business cards on campus; messaging University of Calgary student groups through Facebook; introducing the survey in front of several University of Calgary classes; distributing similar information through the university classroom communication software system (Blackboard ${ }^{\mathrm{TM}}$ ); and placing posters around the University of Calgary campus.

Respondents were asked to complete an online survey that was expected to take approximately 15 - 20 minutes about their experience of sports injury. All potential respondents completed an informed consent form be- 
fore taking the survey. The informed consent form stressed the voluntary nature of the respondent's participation, the anonymity of the information provided, and directions should the respondent decide to withdraw from the study at any time. Although efforts were made to get a diverse sample of University of Calgary students in terms of gender, sport played, and level of play, ours is a convenience sample and is not representative of all University of Calgary students.

To measure University of Calgary students' experiences with sports injury, a novel quantitative survey instrument was created. The survey was administered through an online survey tool, Survey Monkey ${ }^{\mathrm{TM}}$ (Survey Monkey, 2012). Students were first asked to provide basic sociocultural demographic information such as sex, age and country of origin (Canada or elsewhere). Next, their participation in sport was assessed in terms of what type of sport they played, what level they played at, and with whom they played.

Because of the diversity of our sample in terms of athletic experience and time spent playing sport, we did not ask respondents about their actual experiences with sports injury. Instead, we asked them about their willingness to play through injuries. First, we asked respondents to check off common injuries (concussion, torn ligament, muscle tear, sprains, bruising, abrasions, fractures, eye injuries, infection, broken nails, broken teeth...) that they would deem warranting medical attention. They were then asked to rate how many of those injuries would cause them to drop out of a competition or match. Based on their responses to these two sets of questions, a variable was generated that represents the percentage of injuries that they would be willing to play through.

In the mid-1990s, Nixon developed a scale to measure the normalization of pain and injury, called the Risk Pain and Injury Questionnaire, which he used to study collegiate level athletes (Nixon, 1994; Nixon, 1996). This scale has since been criticized both in terms of face validity and content validity (Walk \& Wiersma, 2005). Therefore, although we use some of Nixon's original items in our study, we also adapt and add questions from several qualitative academic sources in order to assess the various potential influences on a sports participant's decision to play while injured (Emery, Meeuwisse, \& McAllister, 2006; Fenton, \& Pitter, 2010; Young \& White, 1995; McEwen \& Young, 2011). We attempted to include questions that reflected all the potential influences on sports participants' propensity to play while injured, and then conducted a factor analysis on all the questions to find emergent themes. A complete list of the questions that were used to measure reasons for playing while injured is included in the Appendix, and the factor analysis is discussed later in the paper.

\subsection{Data Analysis}

Once recruitment was complete, responses were downloaded from Survey Monkey ${ }^{\mathrm{TM}}$ and analyzed using SPSS statistical software version 20.0 (SPSS Inc., 2012). To address our first research question, "Who reports being willing to play sport while injured?” we first conducted descriptive analyses on the sample to examine who reports being willing to play while injured, examining demographic variables and sports-related variables such as the type of sport played and the level of sport played.

To address our second research question, "Why do they report being willing to play while injured?” we conducted a factor analysis on the questions about what influences a respondent to play through injury. These questions were originally created to encompass aspects of the four concepts outlined in the literature review: the sports ethic; athletic identity; culture of risk; and influence of others. The factor analysis was run to determine what groups of influences existed in this sample. The results of the factor analysis will be discussed in detail in the results section.

Once we determined the factors which affected respondents' willingness to play while injured, we next utilized the demographic data from each participant to see how these factors varied according to such social, cultural and demographic variables as sex, type of sport, age, years at university, status on the team, etc. Finally, we ran a series of multiple regression analyses, to determine the joint effects of the sociocultural variables and the factors on the respondents' willingness to play through injuries.

\section{Results}

\subsection{Sample Description}

Table 1 summarizes the demographic, social, and cultural composition of the 275 University of Calgary students who successfully completed the online survey. Of these respondents, $86.9 \%(\mathrm{~N}=239)$ had participated in a sport in the past year. The sample consisted of 177 females (64.4\%) and 98 males (35.6\%). The majority, 
Table 1. Sample descriptive statistics for select demographic and sociocultural variables of respondents, $(\mathrm{n}=275)$.

\begin{tabular}{|c|c|c|c|}
\hline $\begin{array}{c}\text { Demographic/social/cultural } \\
\text { variables }\end{array}$ & Responses & Frequency & Valid percent (\%) \\
\hline \multirow[t]{2}{*}{ Participation in last year } & No & 36 & 13.1 \\
\hline & Yes & 239 & 86.9 \\
\hline \multirow[t]{2}{*}{ Sex } & Female & 177 & 64.4 \\
\hline & Male & 98 & 35.6 \\
\hline \multirow[t]{2}{*}{ Country of origin } & Canada & 226 & 82.5 \\
\hline & Elsewhere & 48 & 17.5 \\
\hline \multirow[t]{2}{*}{ Coach/trainer } & No & 124 & 45.3 \\
\hline & Yes & 150 & 54.7 \\
\hline \multirow[t]{2}{*}{ Type of sport } & Team & 143 & 52.3 \\
\hline & Individual & 131 & 47.7 \\
\hline \multirow[t]{4}{*}{ Level of participation } & Casual/recreational & 119 & 44.9 \\
\hline & Club & 50 & 18.9 \\
\hline & Varsity/provincial & 62 & 23.4 \\
\hline & National/professional & 34 & 12.8 \\
\hline \multirow[t]{9}{*}{ Age (years) } & 18 & 78 & 28.4 \\
\hline & 19 & 53 & 19.3 \\
\hline & 20 & 37 & 13.5 \\
\hline & 21 & 30 & 10.9 \\
\hline & 22 & 27 & 9.8 \\
\hline & 23 & 16 & 5.8 \\
\hline & 24 & 8 & 2.9 \\
\hline & 25 & 9 & 3.3 \\
\hline & $26+$ & 17 & 6.2 \\
\hline
\end{tabular}

82.5\%, of the sample was born in Canada. Just over half of the respondents reported they had a coach or trainer. As expected with a survey targeting University students, 87.7\% of the sample was between the ages of 18 and 23. Respondents cited over 42 distinct sports as their primary sport. For the purposes of this project, we categorized these sports as either "team sport” or "individual sport.” Fifty two percent of respondents reported a team sport as their primary sport.

Importantly, there was a wide range of competition levels represented in the sample. Forty five percent of respondent characterized their level of sport as "Casual/Recreational”, followed by 23.4\% who said they competed at the "Varsity or Provincial" level. Nineteen percent said they competed at the "Club" level, while 13 percent said they competed at the "National or Professional” level.

Given the non-random sampling methods used to recruit respondents, the sample will not be assessed for representativeness.

The main dependent variable of interest is the variable "percent of injuries willing to play through". This variable was generated by first asking respondents who said that they participated in sport in the past year $(\mathrm{N}=$ 239) to check off common injuries (concussion, torn ligament, muscle tear, sprains, bruising, abrasions, fractures, eye injuries, infection, broken nails, broken teeth...) that they would deem warranting medical attention. 
They were then asked to rate how many of those injuries would cause them to drop out of a competition or match. Based on their responses to these two sets of questions, a variable was generated that represents the percentage of injuries that they are willing to play through.

Approximately $30 \%$ of these respondents stated that they would not play through any of the injuries they previously cited as requiring medical attention. However, the remaining $70 \%$ stated that they would be willing to play through from $5 \%-100 \%$ of injuries. With the inclusion of those who would not play through any injuries, the mean of the variable "percent of injuries willing to play through" is $20 \%$, with a standard deviation of $20.9 \%$. Scores ranged from 0 to $100 \%$.

\subsection{Bivariate Analysis}

Table 2 presents the bivariate relationships between the variable "percent of injuries willing to play through" and select demographic and sports-related covariates for those participants who played a sport in the past year.

The independent variables that were statistically significantly related to the variable "percent of injuries willing to play through" (at $p<0.05$ ) were the variables "sex" and "coach/trainer". Women were willing to play through a higher average percent of injuries compared to men (23.2\% versus $15.8 \%)$. Those with a coach or trainer were willing to play through a higher average percent of injuries compared to those without a coach or trainer (23.4\% versus 16.4\%). Importantly, the level of participation, type of sport and country of origin are not significantly related to the percent of injuries an individual is willing to play through in the bivariate analyses. We assess their significance in multivariate analyses in Section 5.3, below.

Table 2. Bivariate relationship between the variable "Percent of injuries willing to play through" and select independent variables.

\begin{tabular}{|c|c|c|c|}
\hline Overall mean & Sample size (N) & $\begin{array}{l}\text { Average percent of injuries } \\
\text { willing to play through (\%) }\end{array}$ & Standard deviation \\
\hline All respondents & 238 & 20.0 & 20.9 \\
\hline \multicolumn{4}{|l|}{ Sex ${ }^{*}$} \\
\hline Male & 88 & 15.8 & 22.1 \\
\hline Female & 150 & 23.2 & 18.0 \\
\hline \multicolumn{4}{|l|}{ Country of origin } \\
\hline Canada & 202 & 20.6 & 21.2 \\
\hline Not Canada & 35 & 19.8 & 20.0 \\
\hline \multicolumn{4}{|l|}{ Level } \\
\hline Casual/recreational & 100 & 17.5 & 20.5 \\
\hline Club & 45 & 17.6 & 19.3 \\
\hline Varsity/provincial & 59 & 25.4 & 19.9 \\
\hline National/professional & 34 & 24.3 & 24.5 \\
\hline \multicolumn{4}{|l|}{ Coach/trainer ${ }^{*}$} \\
\hline No & 100 & 16.4 & 20.4 \\
\hline Yes & 138 & 23.4 & 20.9 \\
\hline \multicolumn{4}{|l|}{ Type of sport } \\
\hline Team & 129 & 18.9 & 19.6 \\
\hline Individual & 108 & 22.3 & 22.5 \\
\hline
\end{tabular}

${ }^{*} p<0.05$ (two-tailed test). Note: Results shown are results of t-test for difference between means for variables with 2 categories, and ANOVA for variables with more than 2 categories. 


\subsection{Factor Analysis}

Table 3 below presents the factor analysis of the questions used to assess what influences whether participants report being willing to play sport while injured. A detailed description of the questions included in each factor is available in the Appendix. A factor analysis aims to examine the covariation among a set of variables (in this case 25 Likert scale questions) and to summarize the relationship between variables by producing a set of factors (Kim \& Mueller, 1978). This factor analysis was run on 25 questions and individual scores were obtained on 5 factors. Varimax rotation was used to identify these five and coefficients below 0.60 were suppressed. Therefore, 15 questions loaded on five factors, and 10 questions were suppressed from the analysis. Together, these five factors explained over $50 \%$ of the variance in the data.

Factor $1(25 \%$ of variance explained; Cronbach's alpha $=0.744)$ includes the following questions: encouraged injured teammate to continue to play while injured; duty as an athlete to play through pain; sacrifice body for sport if necessary; and no pain no gain. We titled this factor "culture of pain". Factor 2 (9\% of variance explained; Cronbach's alpha $=0.762$ ) includes the following questions: called derogatory names if don't play while injured; pain behaviour ignored by teammates; and pain behaviour ignored by coach. We titled this factor "negative external pressure." Factor 3 (7\% of variance explained; Cronbach's alpha $=0.634$ ) includes the following questions: value of sport in society; importance of sport in life; and time per week dedicated to sport. We titled this factor "sports value." Factor 4 (6\% of variance explained; Cronbach's alpha $=0.697)$ includes the questions: prove myself to teammates; performance in every game is evaluated; have to prove myself to coach. We titled this factor “strive for distinction.” Factor 5 ( $5 \%$ of variance explained; Cronbach's alpha $=0.765)$ includes the following questions: remained on field due to weak sub; and remained on field due to being shorthanded. We titled this factor "situation." Together, these factors represent a set of complex reasons that respondents report for being willing to play while injured.

Table 3. Factor analysis of influencers on willingness to play through injury.

\begin{tabular}{|c|c|c|c|c|c|}
\hline \multirow[b]{2}{*}{ Item } & \multicolumn{4}{|c|}{ Factor loading } & \multirow[b]{2}{*}{$\mathbf{V}$} \\
\hline & $\mathbf{I}$ & II & III & IV & \\
\hline Encourage injured teammate to play & 0.708 & & & & \\
\hline Duty as an athlete to play through pain & 0.733 & & & & \\
\hline Sacrifice body for sport if necessary & 0.661 & & & & \\
\hline No pain no gain & 0.662 & & & & \\
\hline Derogatory names & & 0.637 & & & \\
\hline Pain behaviour has been ignored by teammates & & 0.802 & & & \\
\hline Pain behaviour has been ignored by coach & & 0.844 & & & \\
\hline Value of sport in society & & & 0.681 & & \\
\hline Importance of sport in life & & & 0.841 & & \\
\hline Time per week dedicated to sport & & & 0.701 & & \\
\hline Prove myself to teammates & & & & 0.722 & \\
\hline Performance in every game is evaluated & & & & 0.706 & \\
\hline Prove myself to my coach & & & & 0.798 & \\
\hline Remained on field-weak sub & & & & & 0.784 \\
\hline Remained on field-shorthanded & & & & & 0.792 \\
\hline \multirow{2}{*}{$\begin{array}{l}\text { Percent variance explained } \\
\text { Cronbach's alpha coefficient }\end{array}$} & $24.873 \%$ & $8.999 \%$ & $7.066 \%$ & $6.056 \%$ & $4.760 \%$ \\
\hline & 0.744 & 0.762 & 0.634 & 0.697 & 0.765 \\
\hline
\end{tabular}


Table 4 presents findings from the bivariate analysis of the five factors and select sociodemographic variables. Using the five factors that loaded, factor means were calculated and compared across sociodemographic variables. Sex was significantly related to mean factor scores on Factor 1 (culture of pain) and Factor 5 (situation). Males scored significantly higher on Factor 1 (culture of pain) $(0.243 \pm 0.11$, compared to $-.135+-.066$ for females) and Factor 5 (situation) (0.083 \pm 0.11, compared to $-.046+-.069$ for females). Those who responded that they did have a coach or trainer scored significantly higher on Factor 2 (negative external pressure) and on Factor 4 (strive for distinction) compared to those who did not have a coach or trainer. Respondents who were born outside of Canada scored significantly higher on Factor 4 (strive for distinction) compared to Canadian born respondents. Respondents whose primary sport is a team sport scored significantly higher on Factor 5 (situation) compared to those whose primary sport is an individual sport. Unsurprisingly, national/professional and varsity/provincial athletes had significantly higher mean factor scores on Factor 3 (sports value)and Factor 4 (strive for distinction), compared to those who play at the casual/recreational or club level.

In the next section, we conduct multivariate regression analyses to determine which, if any, of these factors has an impact on the percent of injuries a respondent is willing to play through, controlling for the sociodemographic variables.

\subsection{Regression Analysis}

Table 5 shows the full regression model including all factors and all sociodemographic covariates. Variables included in this analysis are: sex, country of origin, coach or trainer, primary sport (team versus individual), level of sport and all five factors.

Table 5 shows that in the complete model, four variables are significantly related to the percent of injuries a respondent is willing to play through at $p<0.05$; sex, primary sport, Factor 1 (culture of pain) and Factor 5 (situation). Females will on average play through 9.4\% (S.E. 2.8\%) more injuries than males, controlling for the other variables in the model. Those who participate in an individual sport will, on average, play through 5.8\% (S.E. 2.6\%) more injuries than those who participate in team sports, controlling for the other variables in the model.

Table 4. Mean factor scores by demographic variables.

\begin{tabular}{|c|c|c|c|c|c|c|c|}
\hline Variable & Category & $\mathrm{N}$ & $\begin{array}{c}\text { Factor 1: } \\
\text { Culture of pain }\end{array}$ & $\begin{array}{c}\text { Factor 2: } \\
\text { Negative } \\
\text { external } \\
\text { pressure }\end{array}$ & $\begin{array}{l}\text { Factor 3: } \\
\text { Sports value }\end{array}$ & $\begin{array}{l}\text { Factor 4: Strive for } \\
\text { distinction }\end{array}$ & $\begin{array}{l}\text { Factor 5: } \\
\text { Situation }\end{array}$ \\
\hline \multirow{2}{*}{ Sex } & Female & 177 & $-0.135 \pm 0.066^{*}$ & $-0.112 \pm 0.073$ & $0.0078 \pm 0.076$ & $-0.036 \pm 0.072$ & $-0.046 \pm 0.069^{*}$ \\
\hline & Male & 98 & $0.243 \pm 0.11^{*}$ & $0.202 \pm 0.098$ & $-0.014 \pm 0.092$ & $0.065 \pm 0.10$ & $0.083 \pm 0.11^{*}$ \\
\hline \multirow{2}{*}{ Coach or trainer } & No & 124 & $-0.11 \pm 0.087$ & $-0.012 \pm 0.077^{*}$ & $-0.36 \pm 0.087$ & $-0.036 \pm 0.076^{*}$ & $0.071 \pm 0.086$ \\
\hline & Yes & 150 & $0.089 \pm 0.080$ & $0.0097 \pm 0.088^{*}$ & $0.30 \pm 0.072$ & $0.030 \pm 0.088^{*}$ & $-0.058 \pm 0.081$ \\
\hline \multirow{2}{*}{$\begin{array}{l}\text { Country } \\
\text { of origin }\end{array}$} & Canada & 226 & $-0.031 \pm 0.066$ & $0.0027 \pm 0.065$ & $0.079 \pm 0.066$ & $-0.0084 \pm 0.067^{*}$ & $-0.025 \pm 0.066$ \\
\hline & Not Canada & 48 & $0.150 \pm 0.136$ & $-0.014 \pm 0.143$ & $-0.383 \pm 0.125$ & $0.062 \pm 0.118^{*}$ & $0.132 \pm 0.134$ \\
\hline \multirow{2}{*}{ Primary sport } & Team & 143 & $0.11 \pm 0.088$ & $-0.023 \pm 0.087$ & $0.094 \pm 0.075$ & $0.0240 \pm 0.0875$ & $0.13 \pm 0.091^{*}$ \\
\hline & Individual & 131 & $-0.12 \pm 0.077$ & $0.021 \pm 0.079$ & $-0.11 \pm 0.092$ & $-0.0236 \pm 0.0790$ & $-0.15 \pm 0.071^{*}$ \\
\hline \multirow{4}{*}{$\begin{array}{l}\text { Level of } \\
\text { competition }\end{array}$} & Casual/recreational & 119 & $-0.129 \pm 0.083$ & $0.033 \pm 0.083$ & $-0.476 \pm 0.091^{*}$ & $-0.108 \pm 0.082^{*}$ & $-0.022 \pm 0.084$ \\
\hline & Club & 50 & $0.160 \pm 0.157$ & $-0.213 \pm 0.151$ & $-0.020 \pm 0.107^{*}$ & $-0.257 \pm 0.143^{*}$ & $-0.044 \pm 0.180$ \\
\hline & Varsity/provincial & 62 & $0.042 \pm 0.108$ & $-0.050 \pm 0.116$ & $0.521 \pm 0.099^{*}$ & $0.224 \pm 0.134^{*}$ & $0.023 \pm 0.114$ \\
\hline & National/professional & 34 & $0.140 \pm 0.222$ & $0.291 \pm 0.217$ & $0.726 \pm 0.126^{*}$ & $0.347 \pm 0.180^{*}$ & $0.100 \pm 0.175$ \\
\hline
\end{tabular}

Note: Mean factor scores reported as: Mean \pm Standard Error. ${ }^{*} p<0.05$ (two-tailed test). Note: Results shown are results of t-test for difference between means for variables with 2 categories, and ANOVA for variables with more than 2 categories. 
Table 5. Regression of percent of injuries willing to play through on socio-demographic variables and factors.

\begin{tabular}{|c|c|c|c|}
\hline & Coefficient (S.E) & Standard error & $p$-value \\
\hline Sex $($ male $=1)$ & -0.094 & 0.028 & 0.001 \\
\hline Coach or trainer $($ has coach $=1)$ & 0.034 & 0.032 & 0.295 \\
\hline Country of origin $($ Canada $=1)$ & -0.002 & 0.037 & 0.950 \\
\hline Primary sport (individual sport $=1$ ) & 0.058 & 0.026 & 0.030 \\
\hline Level of competition ${ }^{*}$ & 0.010 & 0.016 & 0.535 \\
\hline Factor 1: Culture of pain & 0.060 & 0.013 & $<0.001$ \\
\hline Factor 2: Negative external pressure & -0.003 & 0.013 & 0.829 \\
\hline Factor 3: Sports value & 0.013 & 0.015 & 0.390 \\
\hline Factor 4: Strive for distinction & $<0.001$ & 0.013 & 0.971 \\
\hline Factor 5: Situation & 0.031 & 0.013 & 0.013 \\
\hline Model $p$-value & & $<0.001$ & \\
\hline $\mathbf{R}^{2}$ & & 0.171 & \\
\hline
\end{tabular}

*Note: Level of competition is included in this model as an interval ratio level variable. Higher values indicate higher level of play.

In addition, respondents who score higher on Factor 1 (culture of pain) report that they are willing to play through a higher percent of injuries than those who score lower on Factor 1, controlling for sex, having a coach, country of origin, primary sport, level of competition and Factors 2 - 5. Respondents who score higher on Factor 5 (situation) report that they are willing to play through a higher percentage of injuries than those who score lower on Factor 5, controlling for other variables in the model. Overall, this model explains $17.1 \%$ of the variance in scores on the "percent of injuries willing to play through" variable. Interestingly, although it was significant in the bivariate analysis, having a coach does not influence the percentage of injuries participants are willing to play through once we control for the other sociodemographic variables and the five influence factors.

\section{Discussion}

From the bivariate analysis and to answer the first research question about who reports being willing to play while injured, approximately $70 \%$ of the sample are willing to play while injured (across all levels and types of sport). The only demographic factors related to the percent of injuries an individual is willing to play through are sex and whether the individual has a coach. Women were willing to play through $23.2 \%$ of injuries on average, compared to men who were willing to play through $15.8 \%$ of injuries on average. Those with a coach or trainer were willing to play through $23.4 \%$ of injuries on average compared to those without a coach or trainer who were willing to play through $16.4 \%$ of injuries on average.

In terms of why respondents report being willing to play through injury, we discovered five factors in our data: culture of pain; negative external pressure; sports value; strive for distinction; and situation. While these factors do not map neatly onto the four concepts we covered in the literature review (the sports ethic; athletic identity; culture of risk; and influence of others) we believe they are related to previous literature as follows. First, the culture of pain may indicate over-conformity to the sports ethic. Negative external pressure indicates the influence of others, but in a negative way. Sports value may indicate strong athletic identity. The strive for distinction represents aspects of both athletic identity and the influence of others (here in a positive way). Situation, again, may indicate the influence of others although here the influencers are others involved in a specific team competition.

Several socio-demographic variables were significantly related to the factor scores, indicating that different groups may be more or less influenced by the different factors. Level of competition was correlated with both sports value and strive for distinction, with respondents at higher levels of competition reporting higher values on both these factors. These findings suggest that the athletic identity is more relevant for those at higher levels of competition. Those who have a coach had higher average factor scores on strive for distinction and negative external pressure than those without a coach, suggesting that those with a coach may identify more with the athletic identity and are more influenced by others. Men scored higher, on average, on the culture of pain factor 
than women, suggesting that over-conformity to the sports ethic may be more common among men than women. And finally, both men and those on teams (compared to those in individual sports) reported higher average scores on the situation factor, suggesting that they may be more influenced by others, especially in particular competitive situations.

The multivariate analysis indicates that only two socio-demographic variables (sex and individual versus team sport) and only two factors (culture of pain and situation) are significantly related to the percent of injuries respondents report being willing to play through. In our data, level of competition and whether the respondent has a coach or not are not related to their willingness to play through pain, once we account for the effect of all the factor scores and other socio-demographic variables.

Interestingly, although males reported higher levels of mean factor scores on the culture of pain factor and the situation factor (which are both significant risk factors for playing while injured in the multivariate model), females still reported being willing to play through more injuries than males, controlling for all other covariates. Once we controlled for the other demographic variables and the factors, women were, on average, reporting that they were willing to play through $9.8 \%$ more injuries than their male counterparts. Additionally, those who participate in individual sports were, on average, willing to play through 5.8\% more injuries compared to those who participate in team sports, net of all other covariates in the model. In our multivariate analysis, variables such as level of competition or having a coach or trainer do not seem to matter when it comes to a player's decision to play while injured.

The culture of pain also had a significant influence on percent of injuries a respondent was willing to play through — an increase of one unit on Factor 1 lead to respondents reporting a willingness to play through $6.0 \%$ more injuries, when controlling a variety of covariates and factors. And finally, the situation was also a determinant of a respondents reporting their willingness to play through injuries, a one unit increase in Factor 5 leading to a respondent's willingness to play through 3.1\% more injuries, controlling for other variables in the model.

If we consider the culture of pain factor to indicate one aspect of over-conformity to the sports ethic, it can be argued that our data indicates that stronger adherence to the sports ethic affects both male and female sports participants' willingness to play through injuries at all levels of play. These findings appear to run counter to the conclusions of many qualitative and quantitative studies concerning the reasons athletes play while injured (Nixon, 1993; Charlesworth \& Young 2004; Malcom 2006). For example Malcom’s (2006) study of female baseball players theorized that those players who were higher skilled or had more invested in their sport in terms of money and time, were more likely to adhere to the sports ethic, and thus more likely to play through the pain. Our study included a wide range of participants, in terms of level and type of sport. The relative insignificance of factors beyond the sport ethic and sex in our findings may indicate that these variables only have an impact on athletes in specific settings (e.g. professional baseball players).

Many researchers have shown that there is little difference between women and men in their adherence to the sports ethic (Charleswood \& Young, 2004; Sabo 2004; Theberge, 1997). Interestingly, in our data it appears that although female sports participants score lower on the culture of pain factor, they are more willing to play while injured than men. Malcom (2006) found that some females initially resisted the tenet of the sport ethic but eventually conformed. Slogans such as "no pain, no gain” may not resonate as much with the university-aged women in our sample as they do with the men, but the women appear to be more willing to play through injuries than the men. Our research suggests that sports injury prevention programs need not just to include women, but indeed to be focused on them.

As suggested by others, sports medicine and sports injury prevention programs must also critically examine how sports participants at all levels of competition come to accept the sports ethic, internalize the athletic identity, and then become part of the culture of risk that exists within sport (Safai, 2003; Theberge, 1997). Our data supports other researchers' findings that sports participants' willingness to play through pain is influenced by various people involved in sport, such as coaches, officials, teammates, parents and the institutions within sports (Nixon, 1992; Malcolm, 2003; Hughes \& Coakley, 1991). This is important when assessing strategies towards health promotion and injury reduction. Public health practitioners and educators must take into account that once the sports ethic is fully internalized it becomes difficult to employ injury reduction strategies.

Future research should examine when in a child's development is the sports ethic internalized. Given the influence of the sports ethic at all levels and time commitment of sport, it may become internalized at one of a child's first interaction with sport in a structured way, namely, physical education classes in school. If so, the 
environment at school may be a context for adjustment of the factors that foster competition with one's peers and where ideas of masculinity and femininity, and peer pressure all interact to create a culture of risk for students to push themselves beyond comfort to maintain in competition with one another.

\section{Limitations}

This study is limited by a convenience sample, thus the results cannot be generalized to the larger public or the University of Calgary population. In addition, the sample was relatively homogenous in terms of age, years having played their primary sport, country of origin, and ethnic group. The lack of variability in these four variables could have suppressed the potentially significant effects of these variables on the factors of injury rationalization. Another limitation that could have biased the sample was an overrepresentation of more serious athletes rather than average university students in sport.

We did not measure the actual incidences of injury among respondents, merely what they would consider to be a significant injury, and what they would (or would not) play through. Respondents may have felt compelled to answer higher on playing through injuries because of their commitment to their sport, for example. Therefore, this survey only measures self-perception of injury and injury behaviour, not actual behaviour. In addition, the factor scores are also based on respondents' self-perceptions, since they were not asked about actual occurrences of behaviours.

\section{Conclusion}

Upon surveying 275 University of Calgary students regarding their willingness to play sports while injured, we found that respondents report being willing to play through injury at every level of sports participation and in both team and individual sports. One of the influences on a respondent's decision to increase the number of injuries they were willing to play through was their score on the culture of pain factor, which we suggest may indicate over-conformity to the sports ethic. Another important variable in this analysis was sex. Women were willing to play through more injuries than men, even when controlling for other socio-demographic and psychological factors.

If it can be determined which situations are more conducive to the adoption of the sports ethic, for instance, educational settings, it may be possible to alter the environment of sport for future generation of athletes to avoid them harming their bodies by internalizing the value of playing through the pain. When planning sports injury prevention interventions, one must also acknowledge the role of the media in glorifying athletes who play through the pain, and the competitive environments in which all students learn.

\section{References}

Berg, E. C., Migliaccio, T. A., \& Anzini-Varesio, R. (2014). Female Football Players, the Sport Ethic and the MasculinitySport Nexus. Sport in Society, 17, 176-189. http://dx.doi.org/10.1080/17430437.2013.828699

Bondy, F. (1996). Kerri Strug Stands Tall on Injured Ankle, Leads U.S. Gymnastics to Team Gold at 1996 Atlanta Olympics. Daily News.

Brewer, B. W., Van Raalte, J. L., \& Linder, D. E. (1993). Athletic Identity: Hercules’ Muscles or Achilles Heel? International Journal of Sport Psychology, 24, 237-254.

Brogan, J. (2012). Athletes Play through Pain at Their Own Peril. Boston Globe. https://www.bostonglobe.com/lifestyle/health-wellness/2012/09/30/playing-through-pain/64tamog9T1KqLbopctWL8J/sto ry.html

Caine, D., Maffulli, N., \& Caine, C. (2008). Epidemiology of Injury in Child and Adolescent Sports: Injury Rates, Risk Factors, and Prevention. Clinics in Sports Medicine, 27, 19-50. http://dx.doi.org/10.1016/j.csm.2007.10.008

Charlesworth, H., \& Young, K. (2004). Why English Female University Athletes Play with Pain: Motivations and Rationalizations. In K. Young (Ed.), Sporting Bodies, Damaged Selves: Research in the Sociology of Sport (pp. 163-180). Oxford, UK: Elsevier. http://dx.doi.org/10.1016/S1476-2854(04)02008-4

Connell, R. W. (2005). Masculinities (2nd ed.). Berkeley, CA: University of California Press.

Curry, T., \& Strauss, R. H. (1994). A Little Pain Never Hurt Anyone: A Photo-Essay on the Normalization of Sports Injury. Sociology of Sport Journal, 11, 195-208.

Emery, C. A., Meeuwisse, W. H., \& Mcallister, J. R. (2006). Survey of Sport Participation and Sport Injury in Calgary and Area High Schools. Clinical Journal of Sport Medicine, 16, 20-26. http://dx.doi.org/10.1097/01.jsm.0000184638.72075.b7 
Fenton, L., \& Pitter, R. (2010). Keeping the Body in Play: Pain, Injury, and Socialization in Male Rugby. Research Quarterly for Exercise and Sport, 81, 212-223. http://dx.doi.org/10.1080/02701367.2010.10599668

Ginis, K. A. M., \& Leary, M. R. (2004). Self-Presentational Processes in Health-Damaging Behavior. Journal of Applied Sport Psychology, 16, 59-74. http://dx.doi.org/10.1080/10413200490260053

Granquist, M., Podlog, L., Engel, J., \& Newland, A. (2014). Certified Athletic Trainers’ Perspectives on Rehabilitation Adherence in Collegiate Athletic Training Settings. Journal of Sport Rehabilitation, 23, 123-133. http://dx.doi.org/10.1123/JSR.2013-0009

Groom, N. (2015). Are the Blokes This Tough? Young Aussie Woman Rugby Player Becomes Internet Star after Video Emerges of Her Getting Her Nose Broken in a Tackle before She Jumps up to Lay a Bruising Tackle of Her Own. Daily Mail Australia.

http://www.dailymail.co.uk/news/article-3114252/Female-rugby-player-gets-nose-broken-makes-crushing-tackles.html

Hardy, C. J., \& Crace, R. K. (1990). Dealing with Injury. Sport Psychology Training Bulletin, 1, 1-8.

Hargreaves, J. (1994). Sporting Females: Critical Issues in the History and Sociology of Women's Sports. London: Routledge. http://dx.doi.org/10.4324/9780203221945

Hughes, R., \& Coakley, J. (1991). Positive Deviance among Athletes: The Implications of Overconformity to the Sport Ethic. Sociology of Sport Journal, 8, 307-325.

Kimmel, M. (2005). Manhood in America. New York: Oxford University Press.

Leddy, M., Lambert, M., \& Ogles, B. (1994). Psychological Consequences of Athletic Injury among High-Level Competitors. Research Quarterly for Exercise and Sport, 65, 347-354. http://dx.doi.org/10.1080/02701367.1994.10607639

Malcom, N. L. (2006). “Shaking It Off” and “Toughing It Out”: Socialization to Pain and Injury in Girls' Softball. Journal of Contemporary Ethnography, 35, 495-525. http://dx.doi.org/10.1177/0891241605283571

McEwen, K., \& Young, K. (2011). Ballet and Pain: Reflections on a Risk-Dance Culture. Qualitative Research in Sport, Exercise and Health, 3, 152-173. http://dx.doi.org/10.1080/2159676X.2011.572181

Messner, M. (1989). Masculinities and Athletic Careers. Gender \& Society, 3, 71-88. http://dx.doi.org/10.1177/089124389003001005

Miller, A. N. (2008). Self-Presentation and Health-Damaging Behaviors in Sport. Unpublished Master's Thesis, Tallahassee, FL: Florida State University.

Morse, M. (1983). Sport on Television: Replay and Display. In E. A. Kaplan (Ed.), Regarding Television: Critical Approaches: An Anthology (pp. 44-66). Frederick, MD: University Publications of America.

Nixon, H. L. (1993). Accepting the Risks of Pain and Injury in Sport: Mediated Cultural Influences on Playing Hurt. Sociology of Sport Journal, 10, 183-196.

Nixon, H. L. (1994). Social Pressure, Social Support, and Help Seeking for Pain and Injuries in College Sports Networks. Journal of Sport and Social Issues, 18, 340-355. http://dx.doi.org/10.1177/019372394018004004

Nixon, H. L. (1992). A Social Network Analysis of Influences on Athletes to Play with Pain and Injury. Journal of Sport and Social Issues, 16, 127-135. http://dx.doi.org/10.1177/019372359201600208

Nixon, H. L. (1996) Explaining Pain and Injury Attitudes and Experiences in Sport in Terms of Gender, Race, and Sports Status Factors. Journal of Sport and Social Issues, 20, 33-44. http://dx.doi.org/10.1177/019372396020001004

Pargman, D. (2007). Sport Injury: An Introduction and Overview of Related Psychological Issues. In D. Pargman (Ed.), Psychological Bases of Sport Injuries (3rd ed., pp. 17-27). Morgantown, WV: Fitness Information Technology.

Public Health Agency of Canada (2012). Curbing Childhood Obesity: A Federal, Provincial and Territorial Framework for Action to Promote Healthy Weights. http://www.phac-aspc.gc.ca/hp-ps/hl-mvs/framework-cadre/index-eng

Roderick, M., Waddington, I., \& Parker, G. (2000). Playing Hurt: Managing Injuries in English Professional Football. International Review for the Sociology of Sport, 35, 165-180. http://dx.doi.org/10.1177/101269000035002003

Sabo, D. (2004). Pigskin, Patriarchy, and Pain. In P. Rothenberg (Ed.), Race, Class, and Gender in the United States: An Integrated Study (pp. 377). New York: St. Martin’s Press.

Safai, P. (2003). Healing the Body in the "culture of risk": Examining the Negotiation of Treatment between Sport Medicine Clinicians and Injured Athletes in Canadian Intercollegiate Sport. Sociology of sport journal, 20, 127-146.

Safe Kids (2014). Can We Change the Culture of Youth Sports? http://www.safekids.org/press-release/can-we-change-culture-youth-sports

Singer, R. L. (2004). Pain and Injury in a Youth Recreational Basketball League. In K. Young (Ed.), Sporting Bodies, Damaged Selves: Research in the Sociology of Sport (pp. 223-235). Bingley: Emerald Group Publishing Limited.

SPSS for Windows (2012). Statistical Software. Chicago: SPSS Inc.

Survey Monkey (2012). Survey Response Collection Website. www.surveymonkey.com 
Theberge, N. (1997). “It's Part of the Game”: Physicality and the Production of Gender In Women’s Hockey. Gender \& Society, 11, 69-87. http://dx.doi.org/10.1177/089124397011001005

Walk, S. R., \&Wiersma, L. D. (2005). Construct Validity of the Risk, Pain, and Injury Questionnaire. Sociology of Sport Journal, 22, 433-446.

Young, K. (1993). Violence, Risk, and Liability in Male Sports Culture. Sociology of Sport Journal, 10, 373-396.

Young, K. (2012). Sport, Violence and Society. London: Routledge. 


\section{Appendix. Survey Questions}

Q11: How many years have you been playing this sport? (Fill in the blank)

Q15: On a scale from 1 - 10 how much do you value sport in society? (loaded on Factor 3)

Q16: How much time per week do you dedicate to your primary sport (not including travelling)? (loaded on Factor 3)

- More than 10 hours per week

- 8 - 10 hours per week

- 5 - 7 hours per week

- 2 - 4 hours per week

- 1 hour per week

- $\quad$ Under an hour a week

Q17: How would you rate the importance of sports in your life? (loaded on Factor 3)

- Extremely important

- Moderately important

- Slightly important

- Not very important

Q21: Do you feel as if you are in competition with those you train or practice with?

- Yes

- $\quad$ No

Q27: After receiving medical attention for an injury, have you ever disregarded doctors' advice regarding your injury?

- Yes

- No

Q29: If a fellow teammate or training companion were to become injured during a competition I would suggest that they should continue to play. (loaded on Factor 1)

- Strongly disagree

- Disagree

- $\quad$ Neither agree nor disagree

- Agree

- $\quad$ Strongly agree

Q34: I am expected to play through injuries.

- Strongly disagree

- Disagree

- $\quad$ Neither agree nor disagree

- $\quad$ Agree

- Strongly agree

Q35: Stories from my teammates/training companions where they have continued to participate in my sport despite injuries influence my decision to play while injured.

- Strongly disagree

- Disagree

- $\quad$ Neither agree nor disagree

- $\quad$ Agree

- $\quad$ Strongly agree

Q36: I am willing to sacrifice my body for my sport if necessary. (loaded on Factor 1)

- Strongly disagree

- Disagree

- $\quad$ Neither agree nor disagree

- $\quad$ Agree

- Strongly agree

Q37: I have never been encouraged by a teammate or training companion to continue to play while injured.

- $\quad$ Strongly disagree

- Disagree 
- $\quad$ Neither agree nor disagree

- $\quad$ Agree

- Strongly agree

Q38: My pain behaviour (limping, groaning) has been ignored by a teammate or training companion. (loaded on Factor 2)

- Strongly disagree

- Disagree

- $\quad$ Neither agree nor disagree

- $\quad$ Agree

- Strongly agree

Q39: I have been called derogatory names for displaying pain behaviour or taking time off from my sport because of an injury. (loaded on Factor 2)

- $\quad$ Strongly disagree

- Disagree

- $\quad$ Neither agree nor disagree

- $\quad$ Agree

- $\quad$ Strongly agree

Q40: I feel it is my duty as an athlete to play through pain. (loaded on Factor 1)

- Strongly disagree

- Disagree

- $\quad$ Neither agree nor disagree

- $\quad$ Agree

- Strongly agree

Q42: I have been scared to approach my coach or trainer regarding an injury for fear of being told to take time off.

- Strongly disagree

- Disagree

- $\quad$ Neither agree or disagree

- Agree

- Strongly agree

Q43: My displays of pain behaviour (limping, groaning) have been ignored by a coach or trainer. (loaded on Factor 2)

- $\quad$ Strongly disagree

- Disagree

- $\quad$ Neither agree or disagree

- $\quad$ Agree

- $\quad$ Strongly agree

Q44: I have never been encouraged to return to my sport from an injury by my coach or trainer.

- $\quad$ Strongly disagree

- Disagree

- $\quad$ Neither agree or disagree

- $\quad$ Agree

- $\quad$ Strongly agree

Q48: I have ignored an injury because of the importance of the game or competition.

- $\quad$ Strongly disagree

- Disagree

- $\quad$ Neither agree or disagree

- $\quad$ Agree

- $\quad$ Strongly agree

Q49: I have remained on the field while injured because we would be shorthanded if I went off. (loaded on Factor 5)

- Strongly disagree

- Disagree 
- $\quad$ Neither agree or disagree

- Agree

- Strongly agree

Q50: I have remained on the field or continued to play while injured because my substitute would not be a strong enough replacement. (loaded on Factor 5)

- Strongly disagree

- Disagree

- $\quad$ Neither agree or disagree

- $\quad$ Agree

- Strongly agree

Q51: How do you feel about the following statement: “no pain, no gain”? (loaded on Factor 1)

- Strongly disagree

- Disagree

- $\quad$ Neither agree or disagree

- $\quad$ Agree

- $\quad$ Strongly agree

Q53: I have to prove myself to my teammates or to those I train with. (loaded on Factor 4)

- Strongly disagree

- Disagree

- $\quad$ Neither agree or disagree

- $\quad$ Agree

- Strongly agree

Q54: I have to prove myself to my coach. (loaded on Factor 4)

- $\quad$ Strongly disagree

- Disagree

- $\quad$ Neither agree or disagree

- $\quad$ Agree

- $\quad$ Strongly agree

Q55: My performance in every game or competition is evaluated and determines my placement. (loaded on Factor 4)

- $\quad$ Strongly disagree

- Disagree

- $\quad$ Neither agree or disagree

- $\quad$ Agree

- Strongly agree

Q56: I must play through pain to be considered an athlete.

- $\quad$ Strongly disagree

- Disagree

- $\quad$ Neither agree or disagree

- $\quad$ Agree

- $\quad$ Strongly agree 


\section{Submit or recommend next manuscript to SCIRP and we will provide best service for you:}

Accepting pre-submission inquiries through Email, Facebook, LinkedIn, Twitter, etc.

A wide selection of journals (inclusive of 9 subjects, more than 200 journals)

Providing 24-hour high-quality service

User-friendly online submission system

Fair and swift peer-review system

Efficient typesetting and proofreading procedure

Display of the result of downloads and visits, as well as the number of cited articles

Maximum dissemination of your research work

Submit your manuscript at: http://papersubmission.scirp.org/ 